\title{
Pathogenesis of bovine spongiform encephalopathy in sheep
}

\author{
L. J. M. van Keulen · M. E. W. Vromans • \\ C. H. Dolstra · A. Bossers · F. G. van Zijderveld
}

Received: 16 August 2007/ Accepted: 27 November 2007/Published online: 19 December 2007

(C) The Author(s) 2007

\begin{abstract}
The pathogenesis of bovine spongiform encephalopathy (BSE) in sheep was studied by immunohistochemical detection of scrapie-associated prion protein $\left(\mathrm{PrP}^{\mathrm{Sc}}\right)$ in the gastrointestinal, lymphoid and neural tissues following oral inoculation with BSE brain homogenate. First accumulation of $\mathrm{PrP}^{\mathrm{Sc}}$ was detected after 6 months in the tonsil and the ileal Peyer's patches. At 9 months postinfection, $\mathrm{PrP}^{\mathrm{Sc}}$ accumulation involved all gut-associated lymphoid tissues and lymph nodes as well as the spleen. At this time point, $\operatorname{PrP}^{\mathrm{Sc}}$ accumulation in the peripheral neural tissues was first seen in the enteric nervous system of the caudal jejunum and ileum and in the coeliac-mesenteric ganglion. In the central nervous system, $\mathrm{PrP}^{\mathrm{Sc}}$ was first detected in the dorsal motor nucleus of the nervus Vagus in the medulla oblongata and in the intermediolateral column in the spinal cord segments T7-L1. At subsequent time points, $\operatorname{PrP}^{\mathrm{Sc}}$ was seen to spread within the lymphoid system to also involve all non-gut-associated lymphoid tissues. In the enteric nervous system, further spread of $\mathrm{PrP}^{\mathrm{Sc}}$ involved the neural plexi along the entire gastrointestinal tract and in the CNS the complete neuraxis. These findings indicate a spread of the BSE agent in sheep from the enteric nervous system through parasympathetic and sympathetic nerves to the medulla oblongata and the spinal cord.
\end{abstract}

L. J. M. van Keulen $(\bowtie) \cdot$ M. E. W. Vromans .

C. H. Dolstra - A. Bossers - F. G. van Zijderveld

Department of Bacteriology and TSE's,

Central Institute for Animal Disease Control (CIDC),

Wageningen University and Research Centre, P.O. Box 2004,

8203 AA Lelystad, The Netherlands

e-mail: lucien.vankeulen@wur.nl

\section{Introduction}

Since the beginning of the epidemic of bovine spongiform encephalopathy (BSE) in cattle in the UK in 1985, there have been concerns about the possible spread of BSE to other animal species including humans. These concerns were later shown to be (at least partially) justified as BSE has spread to wild and domestic cats and humans through the consumption of meat or byproducts derived from BSEinfected cattle [3, 4, 17]. In addition, BSE has spread to wild herbivores and domestic goats, probably through the ingestion of feed containing BSE-infected meat and bone meal $[3,7]$.

There have been no reports of naturally occurring BSE so far in sheep, although sheep are experimentally susceptible to BSE [8]. Naturally occurring BSE in sheep could present a great danger to both humans and sheep. Meat and byproducts from BSE-infected sheep would present a greater danger to humans than products derived from BSE-infected cattle because, in sheep, BSE infectivity is widespread through the whole lymphoid system (and thereby the whole sheep carcass) [2, 9], in contrast to cattle, where BSE infectivity is primarily limited to the CNS [6, 9, 10]. Furthermore, BSE could theoretically become endemic in the sheep population as has been demonstrated in experimentally infected sheep flocks, where BSE was seen to spread from ewe to lamb either in utero or at birth [1]. This would mean that BSE in sheep would be as difficult to eradicate as natural scrapie, where all attempts at eradication so far have had limited effects. Breeding programmes to select for sheep with PrP genotypes associated with relative resistance to scrapie (and BSE) have decreased the incidence of scrapie in affected flocks, but it is still uncertain if these programmes will eventually lead to the eradication of scrapie. The latter has 
been questioned by the appearance of atypical scrapie and the successful intracerebral transmission of BSE to sheep previously thought to be resistant to transmissible spongiform encephalopathies (TSEs) [5, 13].

Recently, the EU has stepped up the surveillance of TSEs in small ruminants. Both slaughtered sheep or goats and fallen stock are sampled for testing by one of the EUaccredited TSE tests for small ruminants. In the case of a positive result, further tests are done to discriminate BSE from scrapie-infected animals. The small ruminant TSE tests are all based on the detection of the scrapie-associated prion protein $\left(\mathrm{PrP}^{\mathrm{Sc}}\right)$ in the obex of an infected sheep or goat. The selection of the obex as sampling site is largely based on our knowledge of the pathogenesis of scrapie in sheep [20]. Whether the obex is as important in the pathogenesis of BSE in sheep is unknown. Previous studies by Bellworthy and others using both immunohistochemistry and bio-assay in mice, have shown $\operatorname{PrP}^{\mathrm{Sc}}$ and infectivity to be widespread in viscera, lymphoid and nervous tissues but did not clarify the pathogenesis of BSE in sheep [2].

In the present study, we have followed up on our previous studies of natural scrapie in sheep. We have used a similar approach combining a sequential time point study with extensive histopathological and immunohistochemical analysis of selected tissues to study the pathogenesis of BSE in sheep. Although the immunohistochemical detection of scrapie-associated prion protein or $\operatorname{PrP}^{\mathrm{Sc}}$ may not be as sensitive as the detection of BSE infectivity through mouse bio-assay, it does offer the great advantage of identifying the cell types and neuro-anatomical pathway(s) involved in the pathogenesis of BSE.

\section{Materials and methods}

Inoculation of sheep with BSE brain homogenate

The experimental infection of sheep with BSE brain homogenate has been described previously (Table 1) [19]. In short, scrapie-free Texel or Texel cross ewes were bred to produce offspring of the ARQ/ARQ and ARR/ARR genotype (genotypes are expressed as the single letter amino acid code present at codons 136, 154 and 171 of the $\operatorname{PrP}$ gene). The PrP genotype of the lambs was checked by full DNA sequencing of the open reading frame of the PrP gene, and no other polymorphisms were detected. Eleven lambs of the ARQ/ARQ genotype were orally dosed at the age of 4-5 months with $5 \mathrm{~g}$ of a BSE brain homogenate administered as $25 \mathrm{ml}$ of a $20 \%$ brain homogenate in the back of the mouth with a disposable syringe. The brain homogenate was kindly provided by Dr. Martin Jeffrey and was also used in previous BSE experiments in sheep in the
Table 1 PrP genotypes of the sheep and the intervals at which they were euthanised after oral dosing with BSE brain homogenate

\begin{tabular}{llll}
\hline $\begin{array}{l}\text { Sheep } \\
\text { number }\end{array}$ & $\begin{array}{l}\text { PrP } \\
\text { genotype }^{\mathrm{a}}\end{array}$ & $\begin{array}{l}\text { Oral dosing } \\
\text { with 5 g }^{\text {of BSE brain }}{ }^{\mathrm{b}}\end{array}$ & $\begin{array}{l}\text { Killed at } \\
\text { (months } \\
\text { postinfection) }\end{array}$ \\
\hline 1 & ARQ/ARQ & + & 6 \\
2 & ARQ/ARQ & + & 9 \\
3 & ARQ/ARQ & + & 12 \\
4 & ARQ/ARQ & + & 13 \\
5 & ARQ/ARQ & + & 15 \\
6 & ARQ/ARQ & + & 17 \\
7 & ARQ/ARQ & + & 19 \\
8 & ARQ/ARQ & + & $20^{\mathrm{c}}$ \\
9 & ARQ/ARQ & + & $21^{\mathrm{c}}$ \\
10 & ARQ/ARQ & + & $23^{\mathrm{c}}$ \\
11 & ARQ/ARQ & + & $24^{\mathrm{c}}$ \\
12 & ARQ/ARQ & - & 72 \\
13 & ARR/ARR & + & 72 \\
\hline
\end{tabular}

${ }^{a}$ PrP genotype was determined by full-length DNA sequencing of the open reading frame of the PrP gene and expressed as the single-letter amino acid code present at codon 136, 154 and 171

b The BSE inoculum was administered as $25 \mathrm{ml}$ of a $20 \%$ BSE brain homogenate in the back of the mouth. The infectivity of the inoculum, as determined by titration in RIII mice, was $10^{3.97} \log _{10}$ mouse intracerebral/intraperitoneal LD50/g of tissue [2]

c Sheep with clinical signs of BSE, consisting of weight loss, pruritus and tremor/ataxia

UK. The infectivity of the inoculum, as determined by titration in RIII mice, was $10^{3.97} \log _{10}$ mouse intracerebral/ intraperitoneal LD50/g of tissue $[2,15]$. The sheep were housed in Biocontainment Level 3 facilities to constrain any BSE infectivity spreading through the faeces and to avoid any risk of cross-contamination with scrapie. One ARQ/ARQ sheep was killed at 6, 9, 12, 13, 15, 17 and 19 months postinfection (mpi). Four sheep were left to develop clinical disease and were killed for welfare reasons once signs of ataxia were noticed. As negative controls, one ARR/ARR lamb was orally infected with the same dose of the BSE brain homogenate and one ARQ/ARQ sheep was left uninoculated and housed separately from the inoculated sheep.

\section{Tissue sampling}

Sheep were killed by intravenous injection of sodium pentobarbital followed by exsanguination. Tissues were sampled in duplicate (brain divided sagitally) with the emphasis on the gastro-intestinal tract, the lymphoid tissues including all gut-associated lymphoid tissues (GALT), the brain, the spinal cord (C1-L6) and the autonomic ganglia. 
One set of samples was fixed in phosphate-buffered formalin ( $\mathrm{pH} \mathrm{7)}$ for $24 \mathrm{~h}$, trimmed and fixed for another $24 \mathrm{~h}$ before routine dehydration and processing into paraffin. The other set of samples was stored at $-70^{\circ} \mathrm{C}$ for future biochemical analysis/bio-assay.

$\operatorname{PrP}^{\mathrm{Sc}}$ immunohistochemistry

Tissue sections $(4 \mu \mathrm{m})$ were deparaffinized in xylene and decreasing gradients of ethanol while the endogenous peroxidase activity was abolished with hydrogen peroxide in methanol. Pretreatment of tissue sections consisted of immersion for $30 \mathrm{~min}$ in formic acid followed by autoclaving for $5 \mathrm{~min}$ in citrate solution ( $\mathrm{pH}$ 6). Immunostaining for the presence of $\operatorname{PrP}^{\mathrm{Sc}}$ was performed with the monoclonal 2G11 (Institut Pourquier, Montpellier, France), which was raised against a synthetic peptide based on the ovine PrP sequence 146-182. After extensive rinsing, sections were incubated with Mouse EnVision ${ }^{\mathrm{TM}} \mathrm{HRP}$ (DakoCytomation, Glostrup, Denmark), followed by incubation with diaminobenzidine containing $0.1 \mathrm{M}$ imidazole. Finally, sections were counterstained with haematoxylin, dehydrated and permanently mounted. When $\mathrm{PrP}^{\mathrm{Sc}}$ was detected in a tissue for the first time, the entire tissue from the animal of the previous kill was screened for the presence of $\mathrm{PrP}^{\mathrm{Sc}}$. For this purpose, the tissue block was completely trimmed up into serial sections of $5 \mu \mathrm{m}$, and multiple sections at $50-\mu \mathrm{m}$ intervals were immunostained for $\operatorname{PrP}^{\mathrm{Sc}}$.

\section{Double immunohistochemistry}

Double immunostaining was performed on lymphoid tissues to identify $\operatorname{PrP}^{\mathrm{Sc}}$ in cells of the macrophage/monocyte lineage. $\operatorname{PrP}^{\mathrm{Sc}}$ immunostaining was performed as described above with the exception that Powervision AP (ImmunoVision technologies, Brisbane, CA, USA) was used as secondary antibody and 5-bromo-4-chloro-3-indoxyl phosphate and nitro blue tetrazolium chloride (BCIP/NBT DakoCytomation, Glostrup, Denmark) were used as substrate to develop an insoluble blue reaction product. After a second autoclaving in citrate solution $(\mathrm{pH} \mathrm{6)}$ to destroy mouse immunoglobulins from the first immunostaining, sections were incubated with mouse anti-human CD68 (Clone Ki-M6, Serotec, Oxford, England), which recognises an intracytoplasmic lysosomal-associated epitope expressed by monocytes and macrophages. After rinsing, sections were incubated with Mouse EnVision ${ }^{\text {TM }}$ HRP (DakoCytomation, Glostrup, Denmark) and NovaRED ${ }^{\mathrm{TM}}$ (Vector Laboratories, Burlingame, CA, USA) to develop an insoluble red reaction product.

\section{Results}

One ARQ/ARQ sheep was sacrificed at each of the following time points after oral BSE inoculation: 6, 9, 12, 13, 15, 17 and 19 mpi. Four sheep were left to develop clinical disease consisting of pruritus, weight loss, head tremor and ataxia and were killed for welfare reasons once signs of ataxia were noticed. Incubation times to terminal disease in these four clinical BSE-infected sheep were 20, 21,23 and 24 mpi. Figure 1 schematically represents the progression of the BSE infection in the ARQ/ARQ sheep as followed by the immunohistochemical detection of $\operatorname{Pr}^{\mathrm{Sc}}$.

At 6 mpi (Fig. 1a), granules of $\mathrm{PrP}^{\mathrm{Sc}}$ were detected in single tingible body macrophages (TBMs) in the gutassociated lymphoid tissues (GALT) of the palatine tonsil (Fig. 2a) and the ileum (Fig. 2b). In the Peyer's patches of the ileum, $\operatorname{PrP}^{\mathrm{Sc}}$ accumulation was very sparse and only detected after thoroughly screening the entire tissue by going through the entire paraffin block and examining multiple sections every $50 \mu \mathrm{m}$. The same approach was applied to other GALT tissues, the gastro-intestinal tissues, the brain stem and the thoracic spinal cord, but no further $\operatorname{PrP}^{\mathrm{Sc}}$ accumulations were found.

At 9 mpi (Fig. 1b), $\operatorname{PrP}^{\mathrm{Sc}}$ was readily detectable in a number of GALT and GALT-draining tissues including the tonsil, retropharyngeal lymph node, Peyer's patches (jejunum, ileum and caecum), mesenteric lymph nodes and ileocaecal lymph node, and also in the spleen. The immunostaining was consistent with the previously described accumulation of $\mathrm{PrP}^{\mathrm{Sc}}$ at the follicular dendritic cells (FDCs) and in TBMs (Fig. 3a). In addition, $\mathrm{PrP}^{\mathrm{Sc}}$ was found in the coeliac-mesenteric ganglion and in the submucosal and myenteric plexus of the enteric nervous system (ENS) at the level of the caudal jejunum and ileum (Fig. 3b). In the CNS, $\operatorname{PrP}^{\mathrm{Sc}}$ accumulation was present in the intermediolateral column (IMLC) of the spinal cord at the level T7-L1 (Fig. 3c) and in the brain stem in the ventral part of the dorsal motor nucleus of the nervus Vagus (DMNV) at the level of the obex (Fig. 3d).

At 12-13 mpi (Fig. 1c), all lymphoid tissues including the non-GALT tissues were positive for $\mathrm{PrP}^{\mathrm{Sc}}$ (Fig. 4a). In addition to the staining of FDCs and TBMs, single cells within the cortical and subcortical sinuses of the lymph nodes and in the marginal zone of the spleen were positive for $\mathrm{PrP}^{\mathrm{Sc}}$. Double immunostaining for CD68 showed colocalization of $\mathrm{PrP}^{\mathrm{Sc}}$ in CD68-positive cells, indicating the mononuclear phagocytic nature of these cells (Fig. 4b). In the ENS, $\operatorname{PrP}^{\mathrm{Sc}}$ accumulation was present from the level of the mid-jejunum to the colon in the 12 months kill and in the caudal jejunum and ileum in the 13 months kill. $\operatorname{PrP}^{\mathrm{Sc}}$ in the IMLC of the spinal cord had spread from segments $\mathrm{T} 2$ to $\mathrm{L} 4$ and from segments $\mathrm{T} 4$ to $\mathrm{T} 13$, respectively (Fig. 4c). In the DMNV, $\operatorname{PrP}^{\mathrm{Sc}}$ was present throughout the 
Fig. 1 Schematic representation of $\mathrm{PrP}^{\mathrm{Sc}}$ accumulation (in red) in the lymphoid tissues, ENS and CNS of ARQ/ARQ sheep orally infected with BSE after a 6 months b 9 months c 12 13 months d 15 months e 17 months and f 19 months and after the onset of clinical disease. Abbreviations: $D M N V$ dorsal motor nucleus of the vagus; $I M L C$ intermediolateral column; $C, T$ and $L$ cervical, thoracic and lumbal segments of the spinal cord; $G N$ ganglion nodosus; GMCC ganglion mesentericum cranialis/ coeliacum; $G S$ ganglia spinalis; $O$ oesophagus; $R$ rumen; $R e$ reticulum; Om omasum; $A b$ abomasum; $D u$ duodenum; Je jejunum; Il ileum; $C a$ caecum; Co colon; Rec rectum; GALT gut-associated lymphoid tissues; GALT Lnn lymph nodes draining from GALT tissues. Only the efferent motor fibers of the autonomic nervous system are shown

\section{a}

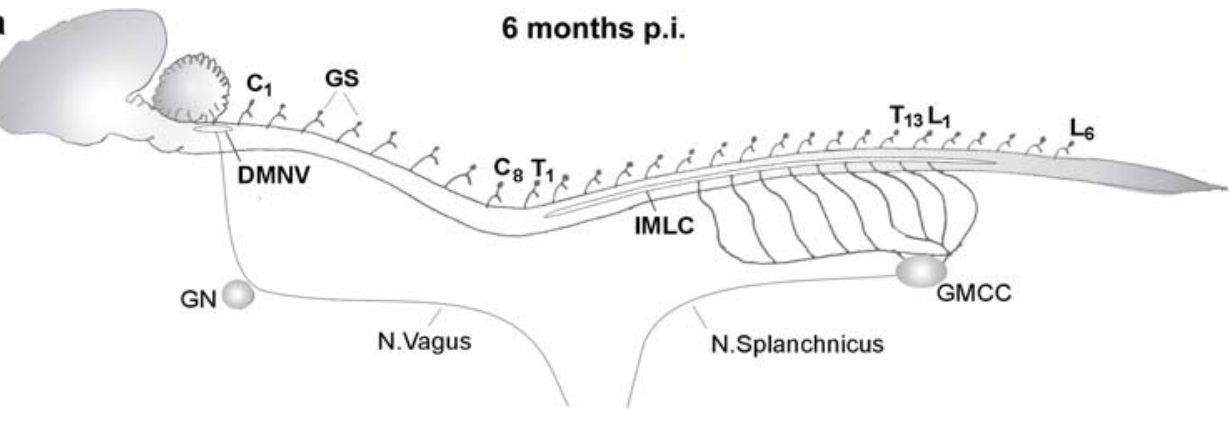

ENS

\begin{tabular}{|c|c|c|c|c|c|c|c|c|c|c|c|c|}
\hline 0 & $\mathrm{R}$ & $\operatorname{Re}$ & Om & $A b$ & Du & Je $25 \%$ & Je $50 \%$ & Je $75 \%$ & il & $\mathrm{Ca}$ & Co & $\operatorname{Rec}$ \\
\hline & & ar & P ile & & & GALT Ln & Sp & leen & & $\mathrm{n}-\mathrm{GAI}$ & Lnn & \\
\hline
\end{tabular}

b

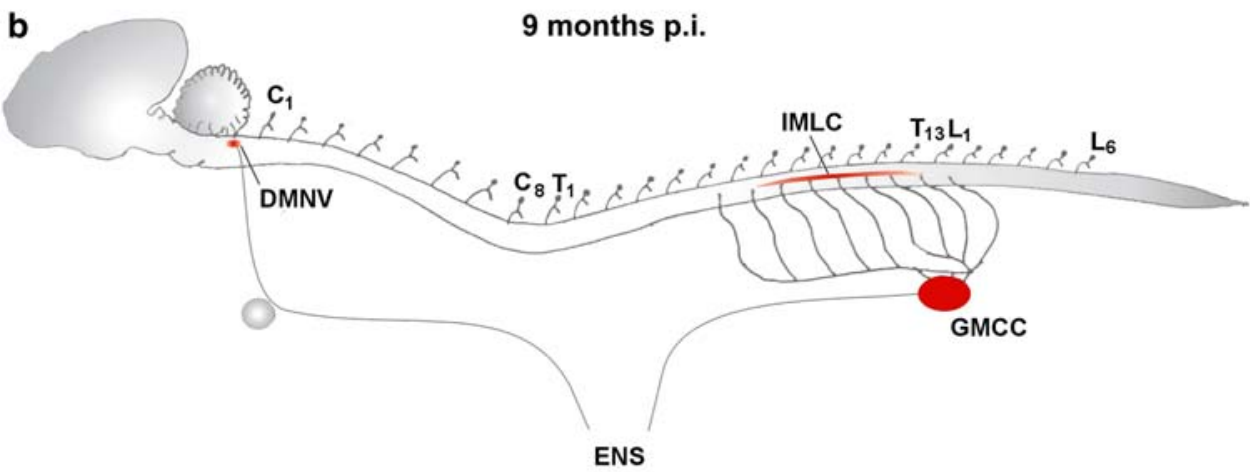

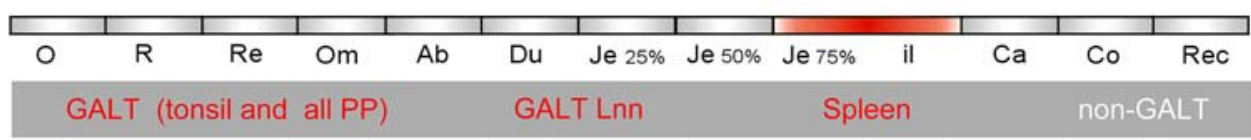

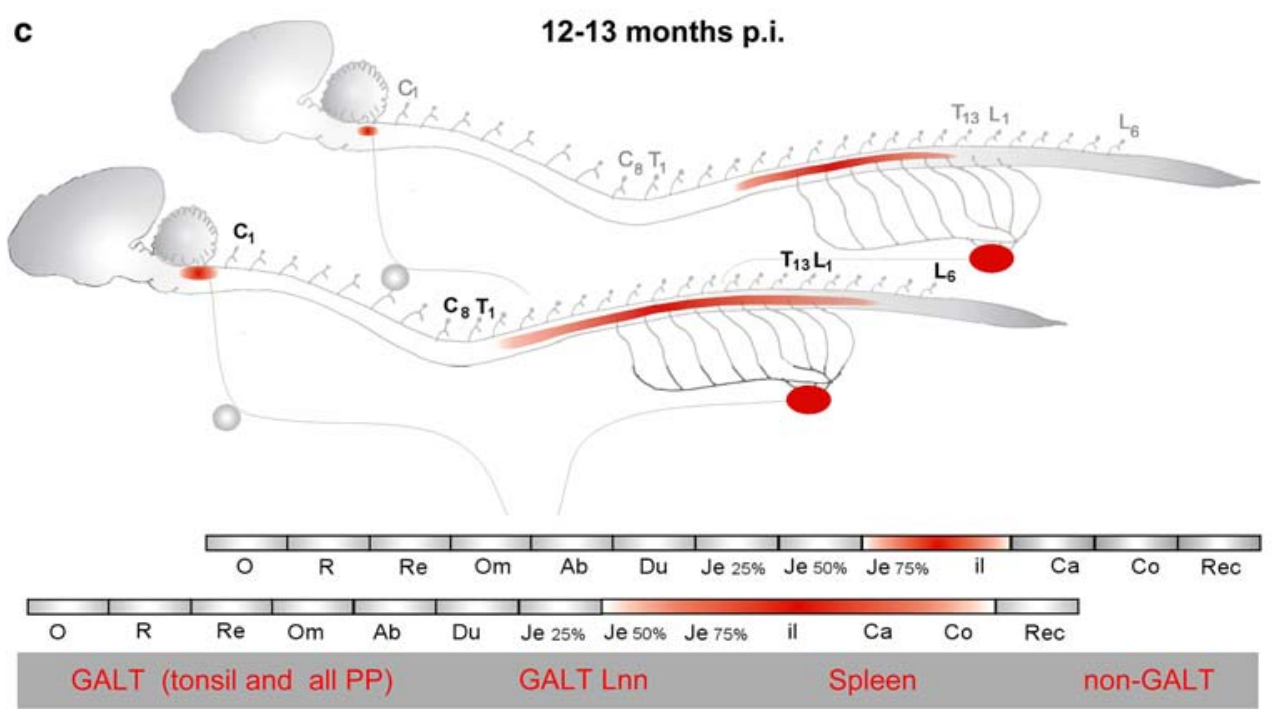

entire length of the nucleus, with additional positive staining in the area postrema in the sheep killed at $12 \mathrm{mpi}$ (Fig. 4d).
At 15 mpi (Fig. 1d), $\operatorname{PrP}^{\mathrm{Sc}}$ in the ENS involved the forestomachs at the level of the omasum and abomasum to the colon. All segments of the spinal cord and most of the 
Fig. 1 continued
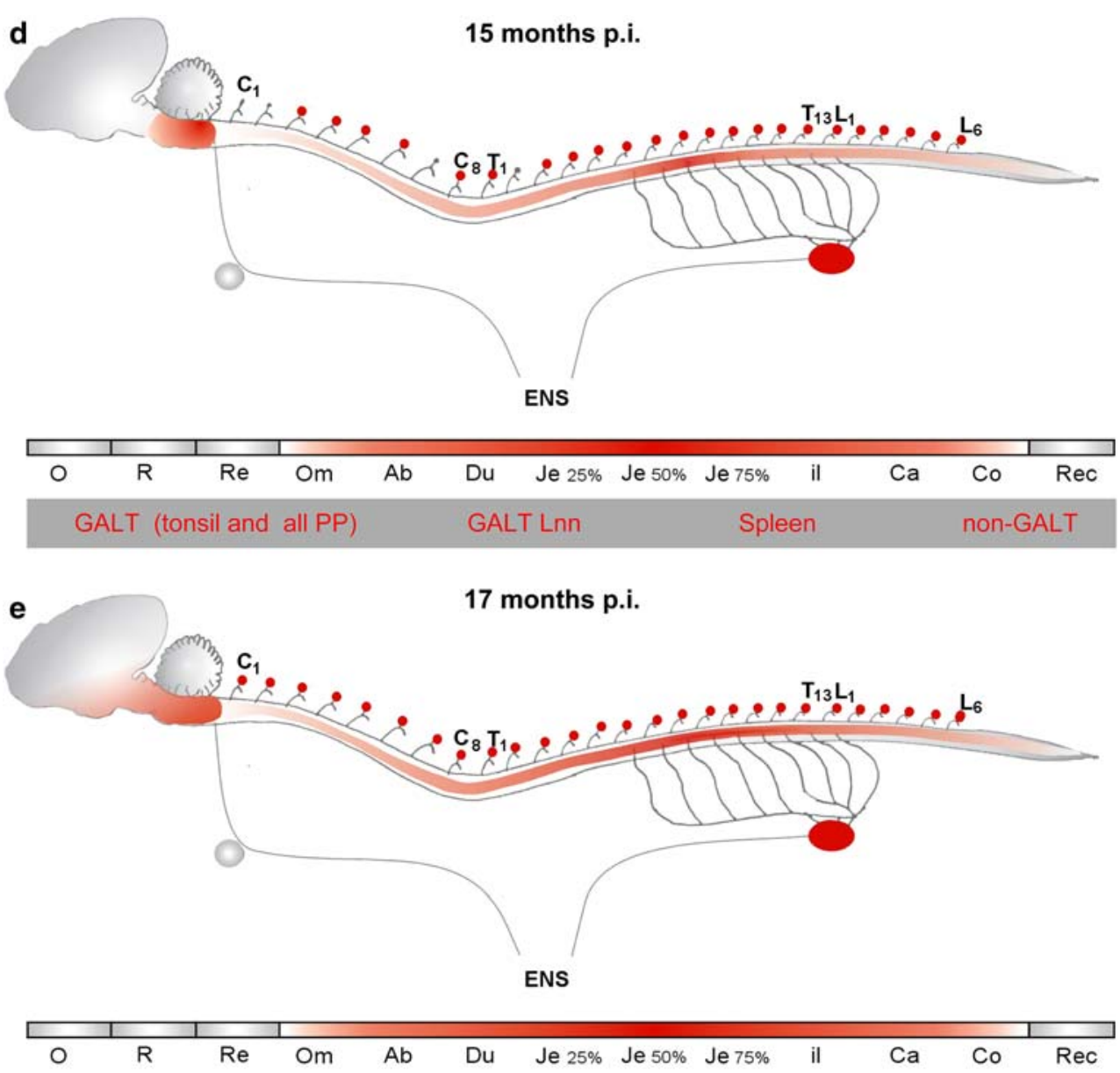

GALT (tonsil and all PP) GALT Lnn Spleen non-GAT

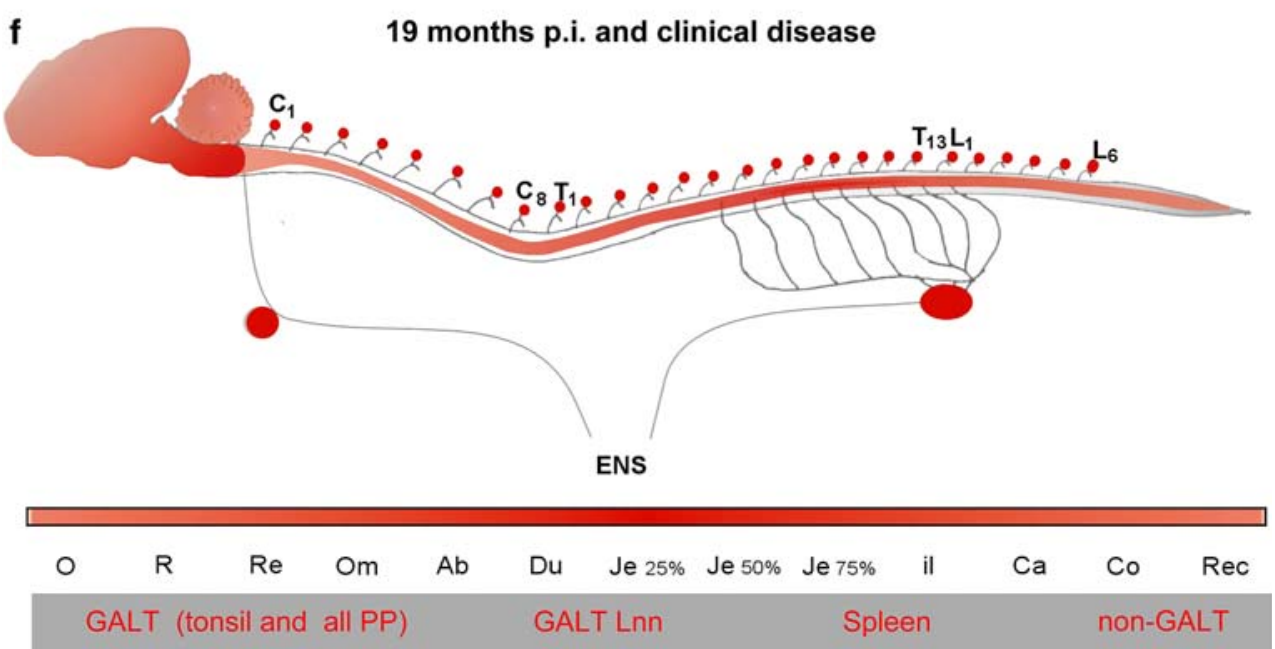

spinal ganglia were positive for $\mathrm{PrP}^{\mathrm{Sc}}$. In the brain, $\mathrm{PrP}^{\mathrm{Sc}}$ accumulation was seen throughout the medulla oblongata and was sparsely seen in some neurons in the pons.

At 17 mpi (Fig. 1e), $\operatorname{PrP}^{\mathrm{Sc}}$ was detected in the ENS from the omasum to the colon. In the CNS, $\mathrm{PrP}^{\mathrm{Sc}}$ was seen in the entire brain stem and in the hypothalamic and thalamic area. All spinal ganglia from the cervical, thoracic and lumbal spinal cord segments were positive for $\operatorname{PrP}^{\mathrm{Sc}}$ at 17 mpi. Prominent vacuolation was present both in the neuropil and within neurons of the DMNV at the obex.

From $19 \mathrm{mpi}$ and in the four clinically affected sheep (Fig. 1f), $\operatorname{PrP}^{\mathrm{Sc}}$ had spread to involve the entire ENS from 


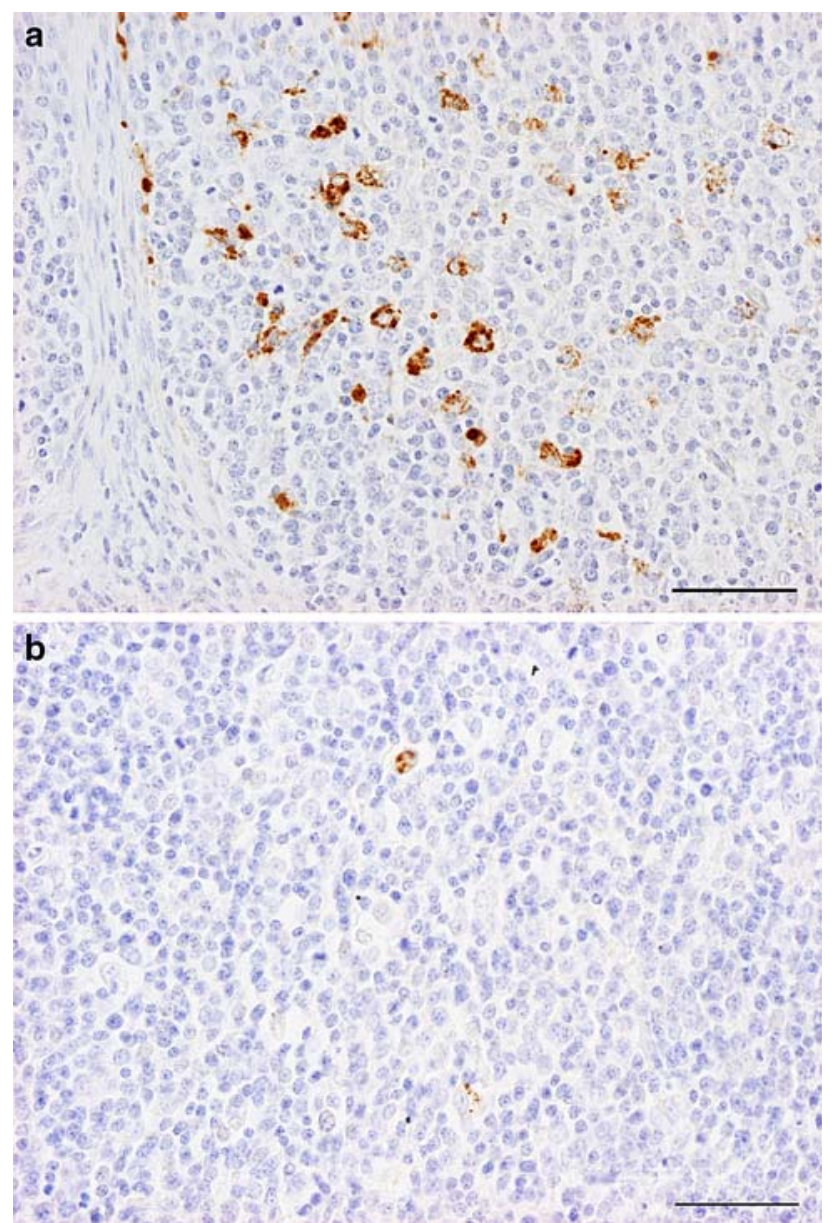

Fig. 2 BSE-infected sheep 6 months after oral inoculation. $\operatorname{PrP}^{\mathrm{Sc}}$ immunostaining of a palatine tonsil and b Peyer's patches of the ileum. $\mathrm{PrP}^{\mathrm{Sc}}$ accumulations are present in tingible body macrophages of the lymphoid follicles. Bar $50 \mu \mathrm{m}$

oesophagus to rectum. $\mathrm{PrP}^{\mathrm{Sc}}$ was detected at all levels in the CNS including cerebellum, basal ganglia and cerebral cortex and in the spinal cord.

The BSE-challenged ARR/ARR sheep and the negative control ARQ/ARQ sheep showed no clinical signs of BSE during the course of the experiment and were euthanised at 72 mpi (Table 1). No $\mathrm{PrP}^{\mathrm{Sc}}$ was detected by immunohistochemistry or Western blotting in the tissues collected from these sheep.

\section{Discussion}

In this study, we investigated the pathogenesis of a BSE infection in sheep by following the accumulation of $\mathrm{PrP}^{\mathrm{Sc}}$ in sheep killed at various time points during the incubation period of BSE. The first tissues to accumulate $\mathrm{PrP}^{\mathrm{Sc}}$ were the lymphoid tissues of the GALT, followed by the GALTdraining lymph nodes and the spleen and, at a later stage, the non-GALT lymph nodes. The temporal spread and pattern of $\operatorname{PrP}^{\mathrm{Sc}}$ deposition in the lymphoid tissues were similar to those described previously for natural scrapie [21, 22]. In the spleen of the BSE-infected sheep, however, a more abundant accumulation of $\operatorname{PrP}^{\mathrm{Sc}}$ was seen in macrophages of the marginal zone. This probably reflects an active trapping and phagocytosis of $\operatorname{PrP}^{\mathrm{Sc}}$ during a systemic circulation of the BSE agent. This is in agreement with the studies of Houston et al., who demonstrated the presence of infectivity in the blood of orally BSE-infected sheep, both in the preclinical and clinical phase, by the transmission of BSE to TSE-free recipients through wholeblood transfusion [12, 14]. The question remains which fraction of the blood contains BSE infectivity and thus whether the BSE agent is present in blood plasma or whether it is associated with a cellular component of the blood. Preliminary results from transfusion with blood fractions have shown infectivity in the buffy coat but could not exclude infectivity in plasma and/or red cell fractions [14].

The first peripheral nervous tissues to accumulate $\operatorname{PrP}^{\mathrm{Sc}}$ in the pathogenesis of BSE in sheep were the post-ganglionic parasympathetic motor neurons in the submucosal and myenteric plexi of the ENS and the post-ganglionic sympathetic motor neurons in the coeliac-mesenteric ganglion. The first accumulations of $\operatorname{PrP}^{\mathrm{Sc}}$ in the CNS were detected in the pre-ganglionic parasympathetic motor neurons of the DMNV in the brain stem and in the preganglionic sympathetic motor neurons of the IMLC in the spinal cord. From these initial sites of $\operatorname{PrP}^{\mathrm{Sc}}$ accumulation in the peripheral and central nervous system, $\operatorname{PrP}^{\mathrm{Sc}}$ subsequently spread to involve the entire ENS and CNS. This pathogenetic route of the BSE agent from the ENS through the efferent motor fibers of the autonomic nervous system to the CNS is similar to the pathogenesis of natural scrapie in sheep [20]. In scrapie- and BSE-infected sheep, the preceding infection of the Peyer's patches could possibly play a role in facilitating the infection of the post-ganglionic motor neurons of the ENS. In cattle orally exposed to BSE, infectivity has also been found in the Peyer's patches of the ileum [23, 24]. Preliminary observations on the pathogenesis of BSE in cattle indicate a similar spread of the BSE agent from the gut through the efferent autonomic nervous system to the CNS [11]. However, the role of the ENS in the pathogenesis of BSE in cattle is still obscure as $\mathrm{PrP}^{\mathrm{Sc}}$ was not found in the ENS during the early stages of a BSE infection and only sparsely in the myenteric plexus of cattle in the end stage of BSE [18].

The results of the present study can be compared with previous time course studies on BSE in sheep in which the same dose and the same BSE brain homogenate were used for oral inoculation of ARQ/ARQ Romney sheep. In these studies, infectivity was detected by bio-assay in RIII mice 

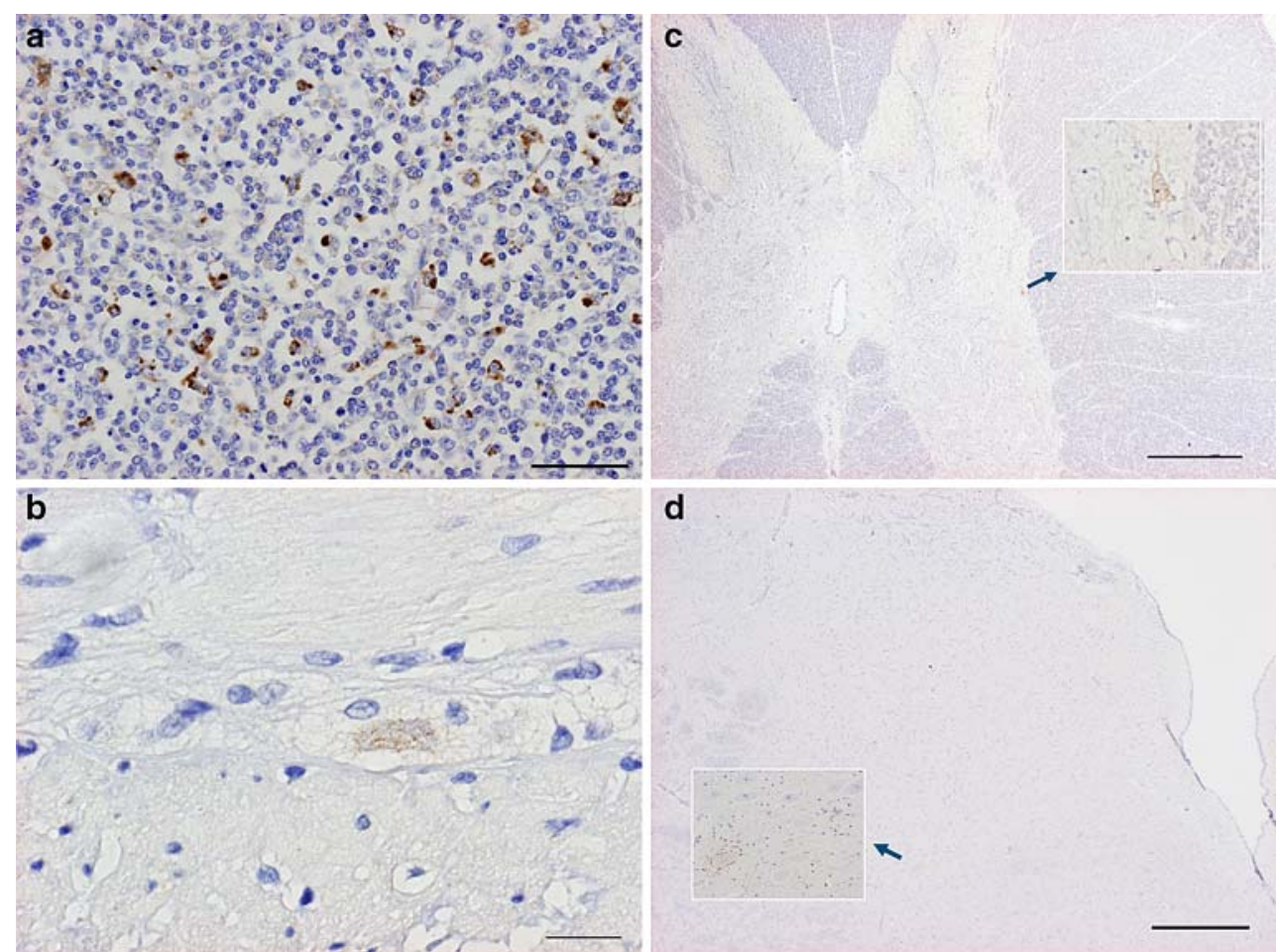

Fig. 3 BSE-infected sheep 9 months after oral inoculation. $\mathrm{PrP}^{\mathrm{Sc}}$

DMNV at the obex. Note the sparse neuronal cell labelling in the immunostaining in a the Peyer's patches of the ileum $\mathbf{b}$ the myenteric plexus of the ileum c IMLC of the spinal cord segment T10 and d IMLC (inlay in c) and the ventral part of the DMNV (inlay in d). a Bar $50 \mu \mathrm{m}$; b bar $20 \mu \mathrm{m}$; c and d bar $500 \mu \mathrm{m}$

Fig. 4 BSE-infected sheep 12 months after oral inoculation. $\mathrm{PrP}^{\mathrm{Sc}}$ immunostaining in a the Peyer's patches of the ileum $\mathbf{b}$ marginal zone in the spleen $\mathbf{c}$ IMLC of the spinal cord segment $\mathrm{T} 5$ and d DMNV at the obex . Note the colocalization of $\operatorname{PrP}^{\mathrm{Sc}}$ (blue) and marginal zone macrophages (red) in the inlay in $\mathbf{b}$ (arrow). $C A$ central arteriole; $G C$ germinal center; $M Z$ marginal zone. a Bar $100 \mu \mathrm{m}$; b bar $100 \mu \mathrm{m}$; c bar $500 \mu \mathrm{m} ; \mathbf{d}$ bar $500 \mu \mathrm{m}$
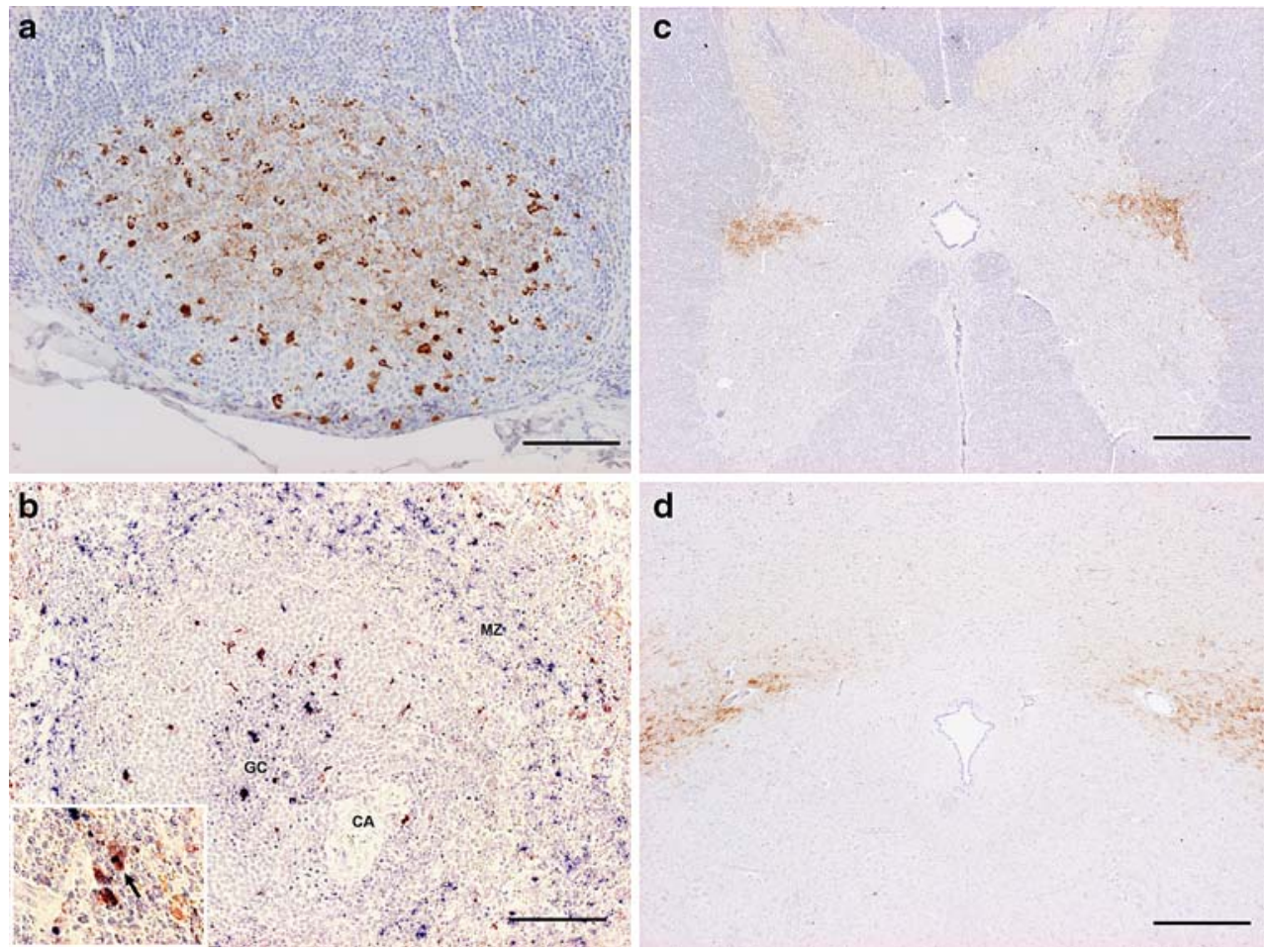

in the Peyer's patches at 4 mpi [2]. In contrast, at this time point, $\mathrm{PrP}^{\mathrm{Sc}}$ was detected immunohistochemically only in the retropharyngeal lymph node and not in the Peyer's patches $[2,15]$. In our study of ARQ/ARQ Texel sheep, we detected sparse deposits of $\mathrm{PrP}^{\mathrm{Sc}}$ at 6 mpi in both the tonsil and Peyer's patches that were only detected after thorough 
screening of the entire tissue by examining sections every $50 \mu \mathrm{m}$ until the blocks were exhausted. This might explain the difference with the immunohistochemical studies in the Romney sheep where $\operatorname{PrP}^{\mathrm{Sc}}$ was only detected in the retropharyngeal lymph node, but it is in general agreement with the bio-assay, where infectivity was found in the Peyer's patches at $4 \mathrm{mpi}$ (but not in the tonsil). In the Texel sheep killed at 9 mpi, all GALT tissues, the spleen, ENS, IMLC and DMNV were positive for $\operatorname{PrP}^{\mathrm{Sc}}$, whereas in the Romney sheep at $10 \mathrm{mpi}, \mathrm{PrP}^{\mathrm{Sc}}$ was only detected in the retropharyngeal lymph node, and infectivity was only detected in the spleen. This indicates a more rapid spread of the BSE infection in the Texel sheep compared to the Romney sheep, since both the dose and the inoculum were the same in the two studies. Because the age at inoculation and the PrP genotypes of the animals in both studies were also the same, the differences in the temporal spread of the BSE agent between the two breeds must be related to other genetic factors outside the PrP region, or to other unknown breed factors. In the Romney sheep, the BSE agent only became widespread at 16 mpi when $\operatorname{PrP}^{\mathrm{Sc}}$ and infectivity were detected in a wide range of nervous tissues, lymphoreticular tissues and viscera including the liver. $\mathrm{PrP}^{\mathrm{Sc}}$ in the liver was reported to be present within Kupffer cells at several stages of the BSE infection (M. Jeffrey, personal communication). In the Texel sheep however, no $\operatorname{PrP}^{\mathrm{Sc}}$ was detected in Kupffer cells or hepatocytes at any stage during the BSE infection.

At present, active surveillance of TSE in sheep and goats has been increased in the EU (EU regulation 214/ 2005) because of the finding of a BSE-infected goat in France [7] and possibly in the UK (confirmation by strain typing is still pending) [16]. Several rapid tests for TSEs in small ruminants are now available (EU regulation 260/ 2005), all of which use the medulla oblongata, and in particular, the obex region as source material for testing. In the present study, we detected $\operatorname{PrP}^{\mathrm{Sc}}$ in the DMNV at the obex of BSE-infected sheep from 9 mpi. In a previous study of natural scrapie in sheep, $\operatorname{PrP}^{\mathrm{Sc}}$ was detected in the DMNV in sheep from 10 months of age [20]. Therefore, preclinically TSE-infected animals are likely to be identified through rapid testing as long as the DMNV region in the obex is excised and used for rapid testing. Further biochemical and/or immunohistochemical tests can then be used to differentiate BSE from scrapie infection, while final confirmation of the TSE strain will still require bio-assay in mice.

Acknowledgments We would like to thank Dr Martin Jeffrey for supplying the BSE brain homogenate. This work was supported by the EU (FAIR CT 98-7006) and the Dutch Ministry of Agriculture, Nature and Food Quality.
Open Access This article is distributed under the terms of the Creative Commons Attribution Noncommercial License which permits any noncommercial use, distribution, and reproduction in any medium, provided the original author(s) and source are credited.

\section{References}

1. Bellworthy SJ, Dexter G, Stack M, Chaplin M, Hawkins SA, Simmons MM, Jeffrey M, Martin S, Gonzalez L, Hill P (2005) Natural transmission of BSE between sheep within an experimental flock. Vet Rec 157:206

2. Bellworthy SJ, Hawkins SA, Green RB, Blamire I, Dexter G, Dexter I, Lockey R, Jeffrey M, Ryder S, Berthelin Baker C, Simmons MM (2005) Tissue distribution of bovine spongiform encephalopathy infectivity in Romney sheep up to the onset of clinical disease after oral challenge. Vet Rec 156:197-202

3. Bruce ME, Chree A, McConnell I, Foster JD, Pearson GR, Fraser H (1994) Transmission of bovine spongiform encephalopathy and scrapie to mice:strain variation and the species barrier. Phil Trans R Soc Lond B 343:405-411

4. Bruce ME, Will RG, Ironside JWW, McConnell I, Drummond D, Suttie A, McCardle L, Chree A, Hope J, Birkett CR, Cousens SN, Fraser H, Bostock CJ (1997) Transmissions to mice indicate that 'new variant' CJD is caused by the BSE agent. Nature 389:498501

5. Buschmann A, Luhken G, Schultz J, Erhardt G, Groschup MH (2004) Neuronal accumulation of abnormal prion protein in sheep carrying a scrapie-resistant genotype (PrPARR/ARR). J Gen Virol 85:2727-2733

6. Buschmann A, Groschup MH (2005) Highly bovine spongiform encephalopathy-sensitive transgenic mice confirm the essential restriction of infectivity to the nervous system in clinically diseased cattle. J Infect Dis 192:934-942

7. Eloit M, Adjou K, Coulpier M, Fontaine JJ, Hamel R, Lilin T, Messiaen S, Andreoletti O, Baron T, Bencsik A, Biacabe AG, Beringue V, Laude H, Le Dur A, Vilotte JL, Comoy E, Deslys JP, Grassi J, Simon S, Lantier F, Sarradin P (2005) BSE agent signatures in a goat. Vet Rec 156:523-524

8. Foster JD, Hope J, Fraser H (1993) Transmission of bovine spongiform encephalopathy to sheep and goats. Vet Rec 133:339-341

9. Foster JD, Bruce ME, McConnell I, Chree A, Fraser H (1996) Detection of BSE infectivity in brain and spleen of experimentally infected sheep. Vet Rec 138:546-548

10. Fraser H, Foster JD (1993) Transmission to mice sheep and goats and bioassay of bovine tissues. In: Transmissible spongiform encephalopathies. A consultation on BSE with the Scientific Veterinary Committee of the Commission of the European Communities, Brussels. Kluwer Academics, Dordrecht, pp 145159

11. Hoffmann C, Ziegler U, Buschmann A, Weber A, Kupfer L, Oelschlegel A, Hammerschmidt B, Groschup MH (2007) Prions spread via the autonomic nervous system from the gut to the central nervous system in cattle incubating bovine spongiform encephalopathy. J Gen Virol 88:1048-1055

12. Houston F, Foster JD, Chong A, Hunter N, Bostock CJ (2000) Transmission of BSE by blood transfusion in sheep. Lancet 356:999-1000

13. Houston F, Goldmann W, Chong A, Jeffrey M, Gonzalez L, Foster J, Parnham D, Hunter N (2003) Prion diseases: BSE in sheep bred for resistance to infection. Nature 423:498 
14. Hunter N, Foster J, Chong A, McCutcheon S, Parnham D, Eaton S, MacKenzie C, Houston F (2002) Transmission of prion diseases by blood transfusion. J Gen Virol 83:2897-2905

15. Jeffrey M, Ryder S, Martin S, Hawkins SA, Terry L, BerthelinBaker C, Bellworthy SJ (2001) Oral inoculation of sheep with the agent of bovine spongiform encephalopathy (bse). 1. onset and distribution of disease-specific prp accumulation in brain and viscera. J Comp Pathol 124:280-289

16. Jeffrey M, Martin S, Gonzalez L, Foster J, Langeveld JP, van Zijderveld FG, Grassi J, Hunter N (2006) Immunohistochemical features of $\operatorname{PrP}(\mathrm{d})$ accumulation in natural and experimental goat transmissible spongiform encephalopathies. J Comp Pathol 134:171-181

17. Pearson GRR, Wyatt JM, Gruffydd Jones TJ, Hope J, Chong A, Higgins RJ, Scott AC, Wells GAH (1992) Feline spongiform encephalopathy: fibril and PrP studies. Vet Rec 131:307-310

18. Terry LA, Marsh S, Ryder SJ, Hawkins SA, Wells GA, Spencer YI (2003) Detection of disease-specific PrP in the distal ileum of cattle exposed orally to the agent of bovine spongiform encephalopathy. Vet Rec 152:387-392

19. Thuring CM, van Keulen LJ, Langeveld JP, Vromans ME, van Zijderveld FG, Sweeney T (2005) Immunohistochemical distinction between preclinical bovine spongiform encephalopathy and scrapie infection in sheep. J Comp Pathol 132:59-69

20. van Keulen LJ, Schreuder BE, Vromans ME, Langeveld JP, Smits MA (2000) Pathogenesis of natural scrapie in sheep. Arch Virol Suppl 16:57-71

21. van Keulen LJM, Schreuder BEC, Meloen RH, Mooij-Harkes G, Vromans MEW, Langeveld JPM (1996) Immunohistochemical detection of prion protein in lymphoid tissues of sheep with natural scrapie. J Clin Microbiol 34:1228-1231

22. van Keulen LJM, Vromans MEW, van Zijderveld FG (2002) Early and late pathogenesis of natural scrapie infection in sheep. Apmis 110:23-32

23. Wells GAH, Hawkins SAC, Green RB, Austin AR, Dexter I, Spencer YI, Chaplin MJ, Stack MJ, Dawson M (1998) Preliminary observations on the pathogenesis of experimental bovine spongiform encephalopathy (BSE): an update. Vet Rec 142:103106

24. Wells GAHH, Dawson M, Hawkins SAC, Green RB, Dexter I, Francis ME, Simmons MM, Austin AR, Horigan MW (1994) Infectivity in the ileum of cattle challenged orally with bovine spongiform encephalopathy. Vet Rec 135: 40-41 